\title{
Preservice teachers' objectives and their experience of practical work
}

\author{
V. Nivalainen, M. A. Asikainen, and P. E. Hirvonen \\ Department of Physics and Mathematics, University of Eastern Finland, P.O. Box 111, FI-80101 Joensuu, Finland
}

(Received 3 April 2011; revised manuscript received 3 December 2012; published 7 January 2013)

\begin{abstract}
This study explores third-year preservice physics teachers' $(n=32)$ views concerning the objectives of practical work at school and university. Content analysis of their essays about practical work revealed not only the objectives of the practical work undertaken but also how they had experienced teaching as school and university students. The objectives most commonly referred to were related to the connections between theory and practice, motivation, understanding phenomena, learning how to observe, and learning how to report. In contrast, some objectives were recognized only rarely, which is an important issue for discussion as a future challenge. Preservice teachers' positive experiences of practical work resulted from the successful implementation of practical work. According to our findings, practical work can in many cases be regarded as successful, especially when the participants understand the objectives of the teaching. In contrast, negative experiences reflected failures or difficulties in implementation. We conclude by suggesting that preservice teachers should be offered opportunities to reflect on their previous experiences and to see and experience in practice the advantages of practical work.
\end{abstract}

DOI: 10.1103/PhysRevSTPER.9.010102

PACS numbers: 01.40.J-

\section{INTRODUCTION}

In this paper we discuss the objectives and perceptions of preservice physics teachers' that they have expressed about their experiences in undertaking practical work. In terms of our thinking, practical work means all the experimental activities that can be done in the classroom or laboratory, including demonstrations, work done by course participants, simulations, and computer modeling (see Refs. [1-5]). Even though the objectives of practical work have been discussed widely in the literature over the past four decades [5-12], research has paid little attention to preservice teachers' previous experience of practical work as part of physics teaching and learning at school or university.

Previous experience plays an important role in knowledge construction because people construct new knowledge and understanding based on their preknowledge and beliefs [13]. As a consequence, the effective teaching of practical work has to be based on investigation of preservice teachers' conceptions, beliefs, and previous experiences. Teacher educators can design learning activities that allow preservice teachers to reexamine and alter their previous understanding while the teacher education program is in progress [14]. Reexamination and reflection are important functions if learning is defined as a process where knowledge is created though the transformation of experience [15]. The reflection-based transformation of one's experience creates a meaningful foundation for

Published by the American Physical Society under the terms of the Creative Commons Attribution 3.0 License. Further distribution of this work must maintain attribution to the author(s) and the published article's title, journal citation, and DOI. physics teachers' education, and at a later stage it provides a foundation for understanding the implementation of practical work in physics teaching at the school level [16].

In the present study we asked preservice physics teachers $(n=32)$ to write a reflective essay about their previous experience of practical work in physics lessons at school and university. Our aim was to help them to become aware of their previous experience and to gain insight into the variety of their experiences as teacher educators. Our first research question was the following:

(1) What objectives do preservice physics teachers express for practical work when reflecting on their previous experience of practical work?

After completing preliminary data analysis, we observed that our subjects' previous experience gained in the course of practical work frequently involved positive or negative loads. To find out more about these potentially interesting positive and negative experiences, we posed another research question:

(2) What are the main positive or negative observations that preservice teachers express in relation to their experiences with practical work in the course of their education?

In the following sections of this paper we discuss the objectives of practical work as presented previously in the literature in order to gain an understanding of the kind of objectives of practical work that are regarded as important by the best-known scholars. The theoretical background consists of position papers that concretize and summarize the objectives for teachers and also papers that are based on empirical research into teachers' and students' views concerning the objectives of practical work. In addition, we investigate studies that have dealt with teachers' and students' views of the roles or objectives of practical work. Our subject group, consisting of preservice teachers, will 
eventually qualify as teachers and hence it is reasonable to examine teachers' views. Students' views of the objectives are also discussed since our subject group formulated their own views about their objectives while they were still pupils and students themselves. The results will allow us to discuss how preservice teachers understand the objectives of practical work based on their school experience and three years' experience of a teacher education program concentrating mainly on the disciplines. Further discussion is still needed so that teacher educators can build up their students' understanding to a sufficient level that will enable them to manage the main aspects of practical work.

\section{OBJECTIVES OF PRACTICAL WORK}

Our intention has been to examine the background literature dealing with the objectives of practical work primarily in the field of physics. In addition, however, a number of well-known articles focusing on general science were also included, since some educational systems do not distinguish precisely between the different disciplines. In order to understand the various views of the objectives of practical work, we will first briefly introduce the goals set by position papers and then examine the research articles, which will in turn provide a general background for the study as a whole.

\section{A. Objectives of practical work presented in position articles}

Kirschner and Meester [5] identify the objectives of practical work as what they term the end terms of a study program and of the general and specific objectives of practical work. End terms consist of the process of obtaining good scientific attitudes and understanding the nature of science. The general and specific objectives of practical work are presented in eight categories, which students are expected to learn: (1) to formulate hypotheses, (2) to solve problems, (3) to use knowledge and skills in unfamiliar situations, (4) to design experiments to test hypotheses, (5) to use laboratory skills in performing experiments, (6) to interpret experimental data, (7) to describe an experiment clearly, and (8) to remember the central idea of an experiment across a long time span.

Shulman and Tamir [7] proposed a categorization of the objectives of practical work based on various lists of objectives that had been previously determined. According to their review, the main objectives should be (1) skills, (2) concepts, (3) cognitive abilities, (4) understanding the nature of science, and (5) attitudes. Subsequently, the American Association of Physics Teachers (AAPT) [10] suggested five main categories for the objectives of practical work: (1) the art of experimentation, (2) experimental and analytical skills, (3) conceptual learning, (4) understanding the basis of knowledge in physics, and (5) developing collaborative learning skills. More recently, Hofstein and Lunetta [11] have stated that practical work enhances students' progress in terms of 1) understanding of scientific concepts, (2) interest and motivation, (3) scientific practical skills and problem solving abilities, (4) scientific habits of the mind, (5) understanding of the nature of science, (6) methods of scientific inquiry and reasoning, and (7) application of scientific knowledge of everyday life. They also mention that the use of practical work facilitates collaborative social relationships.

White [9] suggests that the use of practical work should support training in scientific method as well as promoting skills in precise movements in terms of precision and care. He also suggests that practical work can encourage cooperation and enhance participants' social skills. In addition, he thinks that the main purpose of laboratories is to assist with understanding facts and explanations. Woolnough [17] states that the main aims of teaching science are to help students to understand the principles and theories of science and to understand the way in which scientists work.

In the course of our research we have noticed that in published articles some objectives or categories of objectives appear more often than others. Differences between scholars' views do, however, exist, and hence there is a need for a revised categorization for the main objectives of practical work that will cover the full range of possible objectives. As a consequence, we collected the published articles and formulated six main objective categories of practical work (see Table I). Several of the objectives of practical work are included in each category, and these should be considered as general topics. It is not possible to categorize objectives exclusively, and hence there is some overlap in the categorization. The categorization is also used later in this article as a basis for analysis of preservice teachers' views about practical work.

\section{Developing practical or experimental skills}

All of the researchers reviewed in Table I emphasized the use of practical work for enhancing students' skills and abilities in, e.g., formulating hypotheses, designing experiments, observing, interpreting data, handling errors, and reporting. For example, AAPT [10] labels such skills as "experimental and analytical skills," and Hofstein and Lunetta [11] call them "scientific practical skills and problem solving abilities." To merge this range of aspects related to the same domain, we entitled this category "developing practical or experimental skills."

\section{Developing an understanding of science content and conceptual understanding}

Conceptual understanding and learning of content are seen as one of the most important objective by several authors [7,10]. White [9], for instance, addresses the notion that practical work should reveal links between different topics and that learning with a deep understanding of facts and explanations should be the core purpose of practical work. Woolnough [17] argues that a student's personal 
TABLE I. The main objective categories of practical work formulated by different scholars.

\begin{tabular}{|c|c|c|c|c|c|}
\hline & $\begin{array}{c}\text { Developing } \\
\text { practical or } \\
\text { experimental skills }\end{array}$ & $\begin{array}{l}\text { Developing an } \\
\text { understanding of } \\
\text { science content } \\
\text { and conceptual } \\
\text { understanding }\end{array}$ & $\begin{array}{c}\text { Fostering } \\
\text { motivation }\end{array}$ & $\begin{array}{l}\text { Developing an } \\
\text { understanding of } \\
\text { the nature of } \\
\text { science and of } \\
\text { scientific process }\end{array}$ & $\begin{array}{c}\text { Enhancing social } \\
\text { and learning skills }\end{array}$ \\
\hline $\begin{array}{c}\text { Shulman and } \\
\text { Tamir [7] }\end{array}$ & $\mathrm{X}$ & $\mathrm{X}$ & $\mathrm{X}$ & $\mathrm{X}$ & \\
\hline $\begin{array}{l}\text { Beatty and } \\
\text { Woolnough [8] }\end{array}$ & $\mathrm{X}$ & $\mathrm{X}$ & $\mathrm{X}$ & $\mathrm{X}$ & \\
\hline $\begin{array}{r}\text { Kirschner and } \\
\text { Meester [5] }\end{array}$ & $\mathrm{X}$ & $\mathrm{X}$ & $\mathrm{X}$ & $\mathrm{X}$ & \\
\hline White [9] & $\mathrm{X}$ & $\mathrm{X}$ & $X$ & $\mathrm{X}$ & $\mathrm{X}$ \\
\hline Welzel et al. [18] & $\mathrm{X}$ & $\mathrm{X}$ & $\mathrm{X}$ & $\mathrm{X}$ & $\mathrm{X}$ \\
\hline AAPT [10] & $\mathrm{X}$ & $\mathrm{X}$ & & $\mathrm{X}$ & $\mathrm{X}$ \\
\hline $\begin{array}{l}\text { Hofstein and } \\
\text { Lunetta [11] }\end{array}$ & $\mathrm{X}$ & $\mathrm{X}$ & $X$ & $\mathrm{X}$ & $X$ \\
\hline
\end{tabular}

knowledge of scientific phenomena should be developed by undertaking authentic science. Science teachers, when questioned, also agreed [18] with the view that practical work should connect science concepts and theories discussed in the classroom with observations [11].

Critical opinions have also been expressed about the effectiveness of practical work in developing students' understanding of the science content of their subject. Millar and Abrahams [16], for example, suggest that students seldom learn the things that we want them to learn from practical tasks and, when asked later, students tend to recall only a few of the details of the experiment and cannot remember exactly why the experiment had been undertaken. According to Hodson [19], it cannot be claimed that practical work would be the best method for delivering scientific knowledge if empirical evidence about its efficacy is taken into account. However, the use of practical work offers students an opportunity to examine scientific knowledge from a different perspective from pure theoretical instruction and thus it can be put to excellent use when combined with other types of instruction.

\section{Fostering motivation}

The fostering of the motivation to learn science has been posited as one of the objectives of practical work $[9,17,18]$. Similar results obtained both from empirical studies (e.g., [20]) and from position articles (e.g., [5]) suggest that such objectives also include interest, enjoyment, and satisfaction as desirable affective outcomes of practical work. Furthermore, students' enjoyment of practical work can create positive attitudes and a positive interest in science [11]. On the other hand, as White [9] states, the laboratories are not built to provide enjoyment, but, fortunately, many pupils enjoy the use of laboratories when they study science. One can read from White's text that fostering motivation should be considered to be an implicit objective of practical work, whereas the "serious purposes," as he states, are the explicit ones. We term this category, in brief, "fostering motivation."

\section{Developing an understanding of the nature of science and of scientific process}

The developments of an understanding of the nature of science (NOS) and also of the processes of science are proposed as the objectives of practical work in several of the published articles [7,10,11,21]. The nature of science describes "what science is, how it works, how scientists operate as a social group and how society itself both directs and reacts to scientific endeavors" [22]. Some of the researchers $[5,7,17,18]$ state that students should learn about how scientists develop their scientific thinking. They should also learn about the multiplicity of scientific methods and about the relationship between science and technology. AAPT [10] emphasizes that students should understand that physics is not only a collection of equations but also a structure of concepts, hypotheses, observations, and theories made up of their interrelationship. As an outcome of the teaching that they receive, students should understand not only the content of physics but also the nature of knowledge.

According to Palmquist and Finley [23], understanding the processes of science is a part of understanding the nature of science per se. Millar [24], for example, defines the processes of science broadly as activities that include observing, classifying, inferring, and hypothesizing. Skills such as developing statements from collected data and justifying them in the classroom can be considered the equivalent of gaining an understanding of the process that scientists go through in constructing their knowledge of the natural world [11]. On the other hand, some 
researchers [25] claim that the scientific process is typically oversimplified in teaching, while teaching itself distorts its epistemology and goals. Certainly, teaching scientific process is no easy task for teachers, and they have to simplify the process in order to present some of the ideas concerning scientific process to their students. Several empirical (e.g., [18]) and position articles (e.g., [26]) suggest, however, that an understanding of scientific processes should be an objective of practical work. We have defined this multifaceted category as "developing an understanding of the nature of science and of the scientific process."

\section{Enhancing social and learning skills}

Practical work should also help students to develop in terms of their social and learning skills [10]. White [9] and Beatty and Woolnough [8] state that laboratories should help to develop students' social skills, such as cooperation and their ability to communicate. Hofstein and Lunetta [11] conclude that practical activities have the potential to facilitate collaborative social relationships and to provide opportunities for interaction between students and teacher. Welzel et al. [18] refer to these objectives as the "social dimension." The objective consists of the general skills of communication and interaction, teamwork, and responsibility, for example. However, it should be noted that this objective does not exist in the earlier literature dealing with the objectives of practical work but has emerged in the 1990s, possibly as a result of developments in the field of learning theories.

\section{B. Challenges of practical work at school}

Even though any objective can be linked to practical work, one must bear in mind that not all objectives can be achieved simultaneously $[9,27]$. One of the reasons for failing to achieve the goals of laboratory instruction is that pupils are not aware of the purposes of tasks that they are undertaking, even if their teachers are, as has been demonstrated by Hart et al. [28] in their study. Even if there is some evidence that novice teachers are able to use inquiry in science teaching, some of them might still be incapable or unwilling to use it in their classrooms [29]. As Hodson [27] states, the subgoals of practical work need to be clear so that the demands of the curriculum can be met, since simply doing science is insufficient for promoting either conceptual understanding or an understanding of science per se. Furthermore, a critical and supportive environment is needed when pupils are supposed to be successful in scientific inquiry [30], and alternative ways of using practical work are differently suited for each learning goal. One also has to take into account the fact that not all students are necessarily prepared for the most open-ended laboratories, and hence there is a danger that their studies will lead to failures in experimenting, as demonstrated by Berg et al. [31]. In order to be successful in the classroom, the teacher has to be aware of the students' initial premises and also his or her own strengths and limitations in the use of practical work.

\section{Objectives of practical work in empirical studies}

Teachers' and students' views of the objectives of practical work have attracted the interest of a number of researchers. These views have been examined with the aid of a variety of methods and standpoints, and hence it is difficult to compare the results or to try to make generalizations. In the following, we shall attempt to represent the diversity of these findings by discussing first some of the studies concerning teachers' objectives and then also studies that focus primarily on students' objectives.

\section{Teachers' objectives}

There has been some research interest in teachers' views concerning objectives for students. For instance, in a large European research project in which the views of 60 teachers in six countries and at all school levels were studied, four main objectives for students arose: (a) to link theory and practice, (b) to learn experimental skills, (c) to get to know the methods of scientific thinking, and (d) to foster motivation, personal development, and social competence [18]. In addition, it was found that a teacher's objective is (e) to evaluate the knowledge of students. All the categories include several subcategories.

The contents of categories (b)-(d) are consistent with the literature presented in this article, although the content of category (a), "to link theory and practice," is interesting as being decidedly different from the content of our categorization. The category of "to link theory and practice" has 12 subcategories and some of them could also be categorized differently. For instance, a subcategory labeled "to make the understanding of theory better though practice" could be the main category as such. In addition, a subcategory labeled "to help remember facts and principles" could be considered a part of an understanding of content knowledge and conceptual understanding rather than linking theory and practice.

In a further study, Welzel et al. [18] developed a questionnaire based on this categorization. A total of 406 teachers responded to the survey. The most important main categories considered by the teachers were to link theory and practice, to develop scientific thinking, and to develop experimental skills. In addition, fostering motivation, personal development, and social competence by doing practical work were considered more important at the school level than at the university level. The learning of experimental skills seemed to be more important in university practical work than in secondary school practical work. Welzel et al. [18] explain the result by stating that the aim of university training is to develop professional skills and practices. 
Abrahams and Saglam [32] were interested in discovering possible changes in teachers' views of objectives or practical work in comparison with the results of the pioneering study made by Kerr in 1963 [6]. They examined science teachers' views $(N=388)$ on the 10 aims of practical work presented by Kerr in England and Wales at different stages of education (pupils aged 11-14, 15-16, and 17-18). They discovered that, while there had been no changes in teachers' views with regard to pupils aged 11-14, there had been substantial changes in six of the ten objectives posited by Kerr with regard to students aged 15-16 and 17-18.

In both studies the most important objective of practical work with pupils aged 11-14 was to arouse and maintain interest in the subject. In addition, the least important objective in both studies was preparing pupils for practical work that would be assessed. In the age groups 15-16 and 17-18, present-day physics teachers regard objectives related to interest in and the experience of physical phenomena as more important than did teachers 40 years ago [32]. Furthermore, they regarded the preparation of students for assessed practical work as more important for 15-16-year-old students than did the teachers in Kerr's [6] study. According to Abrahams and Saglam, this is due to the pressure of public scrutiny of the present school system in England and Wales. In contrast, present-day science teachers valued aims related to making accurate observations and to the careful recording and promoting of scientific thinking less than did the science teachers in Kerr's study. However, these aims were considered less important for 17-18-year-old students. Abrahams and Saglam suggest that this is due to the fact that teachers recognize that some of the aims are more important than others at the different levels of secondary education.

Wilkinson and Ward [33] were interested in discovering possible differences in teachers' and students' views of the objectives of practical work. They presented the following ten aims of practical work to Australian high school students and teachers in the form of a ranking task:

(1) To practice making accurate observations and interpreting them

(2) To promote thinking in a scientific way

(3) To gain experience in using scientific equipment

(4) To give training in solving problems and conducting investigations

(5) To prepare students for examinations (the lowest)

(6) To help students understand theoretical parts of science

(7) To provide practice in following a set of instructions

(8) To enable students to discover or verify facts and ideas for themselves

(9) To make science more interesting and enjoyable through actual experience

(10) To develop skills in working cooperatively with others.
Based on the analysis of their results, the three most highly ranked aims, as far as students were concerned, were items 6,9 , and 1 . For teachers, in contrast, the most important aims were 2, 8, and 1. Both students and teachers ranked aims 5 and 7 amongst the three lowest. In addition, the students did not regard aim 10 as important, while the teachers ignored aim 3. In conclusion, it can be seen that students and teachers valued the aims of practical work differently. It seems that from the students' perspective the objectives of practical work appear to be different. When Wilkinson and Ward [33] made a comparison of the rank order of students' and their teacher's views, they found a correlation between students' and teachers' views in only one school. Wilkinson and Ward [33] proposed that this might be due to the fact that some of the teachers presented the aims of their teaching more explicitly than did others.

Teachers' views of objectives for students have usually been studied by means of questionnaires. This has meant that the results are typically presented in terms of the perceived order of importance of several predetermined objectives $[6,18,32,33]$. Because these objective lists and research aims differ, a comparison of the various studies is a demanding task. However, it seems that the objectives of practical work are generally related to the students' age or school level. Teachers emphasize objectives differently with younger pupils than they do with older ones [18,32]. For instance, making science more interesting is considered one of the most important aims with younger pupils, but it is less heavily emphasized with older pupils or university students [32]. Furthermore, the different school levels have their own important objectives, which may be dependent on the current educational system, e.g., a public examination may cause teachers to place more value on the assessment of practical work [32]. It is also possible that students respond to the objectives differently than their teachers have expected, as the results published by Wilkinson and Ward [33] showed, and hence it is important to help future teachers to become aware of the importance of making their teaching objectives visible to their pupils or students. In what follows, students' views of objectives will be examined in greater detail.

\section{Students' objectives}

A few previous studies have been made concerning pupils' or students' views of the purpose or role of practical work. Angell et al. [34] examined how Norwegian 12th and 13th graders understood the purpose of school experiments. Most of the students considered "showing the theory in practice" as the most important aim of practical work. The students did not regard experiments as important or as characteristic of physics. On the other hand, many students considered school experiments interesting. Angell et al. [34] state that 
even if students did not see practical work as a source of new knowledge, many of them argued that school experiments offer new viewpoints and challenge preknowledge. Some students also suggested that school experiments could help in their understanding the concepts of physics. In addition, 10-11-year-old pupils in a study by Braund and Driver [35] argued that the most important reason for doing practical work in science was to find out or learn more.

White et al. [36] investigated first-year university physics students' views concerning practical work $(n=207)$ by means of a survey. When the students were asked what they had gained from their (university level) practical work they mostly agreed with statements about learning how to do experiments (89\%) and developing skills in using equipment $(90 \%)$. However, only $62 \%$ of the students thought that practical work had helped them in understanding theory, while $58 \%$ had gained greater confidence as students of physics. In addition, $40 \%$ of the students experienced enjoyment, but $20 \%$ regarded this as very little. White et al. [36] also asked students about their perceptions of the aims of their lecturers and demonstrators in laboratory classes. The following statements were all rated highly: as a practical application of theory (96\%), acquiring knowledge of how to do experiments in physics (95\%), acquiring expertise in using the equipment $(94 \%)$, understanding why things were happening $(90 \%)$, and understanding what to do in a given experiment (86\%). However, $11 \%$ of the students were not sure about the aims of their lecturers and demonstrators.

Hanif et al. [37] conducted a survey that aimed at investigating university students' perceptions, views, and opinions of physics learning. They focused on first- and second- to third-year students. Results showed that the students' opinions of their experience of practical work in physics were somewhat positive. However, the item "best part of physics" was rejected by most of the students. On the other hand, second- to third-year students regarded practical work as more interesting and enjoyable than did first-year students [37]. When students were asked if practical work helped them to understand physics topics, most of the students in both groups agreed or strongly agreed. The views of second- to third-year students were more positive than those of first-year students [37].

The studies reviewed show that it is challenging to implement practical work so that its objectives are authentically transmitted to students. The students may not see practical work as an essential part of physics helping them in building up their scientific knowledge [34,36]. In particular, university-level practical work may be regarded simply as the technical performance of experiments [37] without necessarily making physics more interesting or enjoyable. Thus, it is important to take preservice teachers' previous experiences explicitly into account in teacher education programs.

\section{METHODOLOGY}

\section{A. Sample}

The data for this study were collected during preservice teachers' third-year spring semester. In Finland a Master's degree is required for a permanent teacher's position at a school. In addition to the Master's studies in the major subject [130 ECTS credits (European Credit Transfer System)], preservice teachers take one or two other subjects as minors (60 ECTS each) together with the subject teachers' pedagogical studies (60 ECTS, general field of education), which provide a qualification as subject teacher. One ECTS credit corresponds to 25-30 hours of work. Physics teachers usually have either mathematics or chemistry as their minor subject, and combinations of all three are relatively common. After graduating, such teachers can apply for posts as physics teachers in lower and upper secondary schools and also in vocational schools.

In total, 32 preservice teachers ( 9 physics, 19 mathematics, and 4 chemistry majors) participated in the study. At the starting point, the participants had been studying for two and a half years at university, had completed almost all of their courses in physics up to 60 ECTS, and were thus completing their initial Bachelor of Science degrees. Their previous studies consisted mainly of theory-based lecture courses that dealt with a variety of different topics related to physics.

Basic laboratory courses for all students, including future physics specialists, are taken during the first year, and intermediate laboratory work is done during the second and third years of their physics studies. Students performed typical university-level experiments, such as Millikan and Planck experiments, where they investigated absolute constants by performing measurements involving relatively challenging apparatus or techniques. The traditional laboratory courses are loosely connected with theory courses but organized separately. In virtually every case, the traditional laboratory experiments undertaken at university are not open ended. The equipment is predetermined, as are the methods prescribed for obtaining and analyzing the data. As a consequence, the results gained from the experiments are usually also predetermined. This type of experimental procedure provides preservice teachers and physicists with only a limited view of the nature of science in general but does introduce some known phenomena and techniques in addition to enabling them to learn how to report their experimental results.

The data for this study were collected halfway through a course on basic laboratory practice for teachers (BLT). This was a first experimental physics course designed especially for preservice subject teachers. The preservice teachers had completed earlier the traditional basic and intermediate level laboratory courses described above. BLT consisted of traditional school experiments; thus, for example, preservice teachers measured the gravitational constant by means of a ticker timer and investigated the 
reflection of waves with a slinky coil. The preservice teachers were required to think about the phenomena by means of questions related to experiments, and they were asked to explain their observations and interpretations to their peers. This generally revealed some of the preservice teachers' preconceptions that would need to be discussed in the teaching.

\section{B. Instruments and data analysis}

In order to answer the first research question, at the beginning of their third spring semester we asked all of the preservice teachers to write an essay (1-2 pages) about "practical work as a part of physics teaching at school and university." The preservice teachers were encouraged to think back to their own school days and to write about their impressions of practical work at lower secondary school (grades 7-9), upper secondary school (grades 10-12), and university. The preservice teachers were also requested to draw up comparisons of the different levels of education reflected in the essays. This task was assigned as follows: "As far as you could see, how did the teaching differ at the different levels of your education, especially with regard to the use of practical work?"

In the present study, our aim was to understand the objectives of practical work that the preservice teachers might express spontaneously. Hence, the use of any kind of questionnaire or list was not an option. If questionnaires had been used, they would have guided the preservice teachers toward selecting objectives that they would not have been able to think of on their own. Furthermore, use of essays as a research instrument gave the preservice teachers sufficient time to respond effectively in the writing task that they were given, in comparison to semistructured interviews, where they would have needed to provide responses quite swiftly. In order to gather more authentic and unbiased data, we also avoided asking in the writing task about the specific objectives of practical work. It has been noted that pupils or students experience difficulty in talking about the objectives of practical work when questioned explicitly because they lack the necessary terminology [37,38], and hence we requested the students to write about practical work in physics teaching in general. We expected to obtain a wealth of data from the essays, where the research participants would in broad terms describe their experience of practical work. From these data, we hoped that we would be able to extract the main details of the objectives of practical work that the students felt important to address. Even if this kind of approach demands more interpretation in the analysis process, we claim that it will yield a more productive discussion compared with data obtained by asking solely about specific objectives of which our research participants would not be aware.

Content analysis [39] was then used in analyzing the data. The first aim of the analysis concentrated on exploring the kind of objectives that preservice teachers set for practical work, and, where possible, also the topics that they tended to ignore. In this theory-driven process, subcategories were established among the written objectives and then collected under the main categories suggested in the theoretical background section. This analysis provided answers to the first research question.

A further content analysis designed to answer the second research question was then conducted to find out about the preservice teachers' experience of practical work. One of the first stages of the content analysis was concerned with identifying the excerpts that described the preservice teachers' experiences in a positive or negative way. This provided the starting point for organizing the quotations into different emergent categories. Next, the quotations were categorized according to the level of the school. Since we had already noted that experiences of practical work at the different school levels had been similar, the data from each level were analyzed in parallel. One of the significant findings that we made was that many positive experiences were indeed related to the six main objective categories already listed above. In addition, on the basis of the data we obtained we were able to characterize some of the features of the teaching that had enabled the subjects to acquire these positive or negative experiences. Their observations may, therefore, be regarded as examples of the various practice modes of instruction that may have an influence on teachers' cumulative experiences.

Researcher triangulation [40] was used in all of the phases of the data analysis in order to improve the credibility of the analysis. The data for the first research question were analyzed as described above, after which another researcher double-checked the subcategories formed and also the quotations taken from the preservice teachers' essays related to each of these subcategories. Quotations containing expressions that relate to the objectives of practical work were then adopted as the coding units for this analysis. A consensus between the researchers about the categorization of the data was achieved after discussion of the seven differences in 122 interpretations (Cohen's kappa $\kappa=0.94)$.

The content analysis for the second research question was conducted in four phases. (1) The first researcher (V.N.) organized quotations according to the respective school level, formulated categories for the data, and selected quotations for each of the categories. He also included notes about his interpretations in the categorization process. Quotations related to the positive or negative experiences were regarded as the coding units for the analysis of this aspect. (2) The data, along with the notes, were given to another researcher (M. A. A.) for analysis, who in turn checked the categorization and made similar notes if any of the quotations from the essays had to be revised. In addition, the second researcher noted one category that was not in the original categorization 
(development of didactical skills and thinking), which was devised in light of the university-level quotations. (3) The first researcher revised the analysis, taking into account the notes of the second reviewer, and then proposed a refined analysis of categories in which the new category was included. (4) A total of nine discrepancies in 206 quotations were found during this phase, and these were discussed in relation to the final version (Cohen's kappa $\kappa=0.95)$.

\section{RESULTS}

\section{A. First research question}

The first research question was concerned with discovering the kind of objectives that preservice physics teachers suggested for practical work when reflecting on their previous experience of practical work. Table II shows the results of our analysis of the teachers' essays. A total of 23 different individual objectives were found concerning all levels of education, an average of 3.81 objectives per essay. These objectives were placed in the six theory-based objective categories. Although every preservice teacher presented, on average, fewer than four objectives, some or all of the objectives may in fact belong to the same main category (e.g., connecting theory with practice and understanding phenomena are both parts of understanding the science content).

In some cases a single objective belonged to two or three main categories. For instance, "to learn to make hypotheses" belonged to three main categories. Kirschner and Meester [5] describe the formulation of a hypothesis in a way that makes it is more closely related to a practical action, whereas Burmester [41] states that planning experiments in order to test hypotheses forms a part of scientific thinking [26]. On the other hand, AAPT [10] claims that hypotheses are a part of the process that produces empirical evidence, which, furthermore, is the basis for understanding how nature works and how laws and theories are formed.

Looking at Table II, the largest main category was "B. Developing an understanding of science content and conceptual understanding." For example, the subcategory "to connect theory to practice" was emphasized by a majority of the research participants (56\%), while "to understand phenomena" was mentioned by one-third $(34 \%)$ of the respondents. The second largest main category was "A. Developing practical or experimental skills." The subcategories "learning to observe (34\%)" and "learning how to report (31\%)" were noted with some frequency. In contrast, categories $\mathrm{C}$ and $\mathrm{D}$ are relatively small and rather similar in size to each other, while the size of category $\mathrm{E}$ is marginal. One exception amongst these categories was "to motivate (41\%)." as many research participants already understood the fact that the use of practical work would enhance student motivation with regard to learning science. On the other hand, several objectives occurred only
TABLE II. Objective categories for practical work in preservice teachers' essays $(n=32)$. The number in the first column is the number of preservice teachers that suggested this item as an objective for practical work. The second column represents the proportion of preservice teachers (as percentages) emphasizing this item in this study. Objectives that belong to several main categories are denoted with an asterisk.

\begin{tabular}{lrl}
\hline \hline$N$ & $\%$ & Objective of practical work \\
\hline \multicolumn{3}{l}{ A. Developing practical or experimental skills } \\
11 & 34 & Learning to observe \\
10 & 31 & Learning to report \\
3 & 9 & Learning to measure \\
3 & 9 & To understand sources of error or inaccuracy* \\
2 & 6 & To learn to make hypotheses* \\
2 & 6 & To become familiar with equipment \\
1 & 3 & To learn about safety
\end{tabular}

B. Developing an understanding of science content and conceptual understanding

$1856 \quad$ To connect theory with practice

1134 To understand phenomena

825 To deepen understanding of content

825 To activate thinking and learning

$7 \quad 22$ To provide another viewpoint of knowledge

39 To compare models and laws of physics to real phenomena*

13 To help to understand the basics of physics

13 To identify preknowledge

C. Fostering motivation

1341 To motivate

413 To entertain

39 Physics is learned as a game

13 To bring credibility to physics

D. Developing an understanding of nature of science and of scientific process

$5 \quad 16$ To verify theory

39 To learn about the nature of physics

39 To understand the sources of error or inaccuracy*

39 To compare the models and laws of physics with real phenomena*

26 To learn how to make hypotheses*

E. Enhancing social and learning skills

26 To learn to work in small groups

26 To offer another way of learning

once or twice. For instance, objectives such as "to learn how to make hypotheses," "to identify preknowledge." and "to learn to work in small groups" were exceptional in the preservice teachers' essays. It should be remembered, however, that the categorization is a product of analyses undertaken by the researchers, so that by selecting the main categories differently, different results may ensue.

It has to be noted that the nature of the categories concerning the main objective is different. It is rather 
easy to recognize objective categories $\mathrm{A}, \mathrm{B}, \mathrm{C}$, and $\mathrm{E}$ in the preservice teachers' essays. For instance, there is no doubt that when the subject tells about how an experiment fostered his or her motivation to learn physics, to state that this recollection is related to the motivational objective. In contrast, objective category $\mathrm{D}$ is more problematic since it frequently remains implicit as a result of students not necessarily knowing about the existence of this particular category of objectives.

\section{B. Second research question}

The second research question was to find what kind of positive and negative experiences preservice teachers had had in their practical work. Table III presents the results of the analysis of preservice teachers' experience of practical work at school and university. We found nine positive and five negative categories of experience. The number of positive experiences $[n=136(+22)]$ was substantially higher than the number of negative ones $(n=47)$. In addition, some of the features of the teaching observed by the preservice teachers that gave rise to the experiences are presented in Table III.

Most of the preservice teachers' positive experiences concerned the development of practical or experimental skills, development of an understanding of the science content and conceptual understanding, and fostering motivation. The first six categories of positive experiences are closely related to the objective categories for practical work presented in Table I in this article. In some cases, there were no clear reasons reflecting their experience of practical work in a positive manner, but several subjects nevertheless considered that the use of practical work generally provided good experiences. Many of the preservice teachers did, however, also refer to specific features of the teaching that they received. They sometimes emphasized, for example, that working in pairs or in small groups enhanced their practical and social skills. In addition, they had already understood as school students that the kind of teaching that focused on student thinking had helped them to overcome their preconceptions and to develop their conceptual understanding of physics.

The category titled "Development of didactical skills and thinking" consists of the experiences involved when a preservice teacher had thought about the teaching of practical work from a teacher's point of view. The influence of the first special laboratory course for preservice teachers can be seen in this category. The development of this kind of understanding is not possible at school and hence we have not included it in the total number of positive experiences.

The preservice teachers had also faced some negative experiences in practical work in the course of their school and university studies, and in many cases it was easier for them to define the origins of their negative rather than their positive experiences. In general, these were related to a teacher's failure to organize practical work, problems in linking theory and practice, or problems concerning a school's equipment and facilities. Occasionally, preservice teachers were disappointed when the practical work did not add to the physics-related content or the experiments did not include anything surprising.

The preservice teachers frequently wrote that the practical work played a significantly smaller role in physics teaching at the upper secondary school than at the lower secondary level. Only four preservice teachers wrote that practical work was used infrequently at lower secondary level. On the other hand, 14 of them suggested that the amount of practical work was small at the upper secondary level.

An interesting observation can be made in the positive category of "practical or experimental skills developed during experimentation." Only a few positive experiences feature in this category at the upper secondary level. Our analysis showed that the preservice teachers participated in doing school experiments more often at lower secondary school than at upper secondary school. The subject group claimed that their upper secondary teachers preferred demonstrations rather than group work done by the students themselves.

In what follows, we will discuss the results in greater detail, relating them to excerpts from the preservice teachers' essays connected with positive and negative experiences and also with the specific features of teaching at school and university. Excerpts from the essays produced by three preservice teachers, Joe, Matt, and Jake, were selected because they expressed typical details that recurred frequently in the essays written by all of the preservice teachers. Positively inclined comments are denoted by a plus sign and negative ones with a minus sign. School levels are denoted by letters related to lower secondary school (LS), upper secondary school (US), and university (U). The number after the school-level code refers to the experiences listed in Table III. A notation "US + 2" would then mean that the quotation is related to upper secondary school and it concerns the development of an understanding of the science content and conceptual understanding, which has been experienced in a positive manner.

Three of the preservice teachers explicitly suggested in their essays that they held a theory-oriented view of the process of learning physics. For instance, the following preservice teacher, Joe, was theory oriented during his lower secondary school and preferred the theoretical examination of physics content:

During the lower secondary school we had lots of group work and experiments. On the other hand I thought that doing experiments was just a waste of time and took time away from the real [theoretical physics] content, which, to my mind, was to calculate problems and learn 
TABLE III. Preservice teachers' $(n=32)$ descriptions of the values and criticism of practical work in their own experience and examples of the teaching features underlying such experiences. LS, lower secondary school; US, upper secondary school; $\mathrm{U}$, university.

\begin{tabular}{|c|c|c|c|c|}
\hline & Experiences of practical work and examples of related features of teaching & LS & US & $\mathrm{U}$ \\
\hline \multirow[t]{12}{*}{ Positive } & $\begin{array}{l}\text { Value 1. Practical or experimental skills developed during experimentation } \\
\text { Underlying features: Working individually or as pairs (LS and US), experiments in which students } \\
\text { gained confidence in their skills, experiments providing new knowledge about equipment (U) }\end{array}$ & 12 & 3 & 18 \\
\hline & $\begin{array}{l}\text { Value } 2 \text {. Understanding of science content or conceptual understanding developed in the course of } \\
\text { practical work } \\
\text { Underlying features: The use of practical work helped to understand concepts and relations between } \\
\text { them (LS and U), a teacher emphasized student thinking (US) }\end{array}$ & 13 & 15 & 29 \\
\hline & $\begin{array}{l}\text { Value 3. It was motivating to do practical work } \\
\text { Underlying features: Opportunities to conduct experiments by themselves was motivating (LS), } \\
\text { understanding theories after seeing experiments motivated (LS and U), practical work generally } \\
\text { improved interest (US and U), opportunities to test experiments that may be used later by the same } \\
\text { subject as a teacher motivated to learn more (U) }\end{array}$ & 9 & 7 & 10 \\
\hline & $\begin{array}{l}\text { Value 4. Understanding of scientific process } \\
\text { Underlying features: Basic experiments resembled the work of physicists (U) }\end{array}$ & 0 & 1 & 2 \\
\hline & $\begin{array}{l}\text { Value 5. Social and learning skills were developed while undertaking practical work } \\
\text { Underlying features: Working in pairs or small groups (LS and U) }\end{array}$ & 2 & 0 & 4 \\
\hline & $\begin{array}{l}\text { Value } 6 \text {. Doing practical work improved understanding the nature of science } \\
\text { Underlying features: Practical work did show how to form hypotheses, select methods, and make } \\
\text { conclusions from the results (U) }\end{array}$ & 0 & 0 & 3 \\
\hline & $\begin{array}{l}\text { Value 7. Practical work offered challenges } \\
\text { Underlying features: Teacher stimulated students to think (LS and US), finding the proper means of } \\
\text { experimenting (U) }\end{array}$ & 2 & 3 & 3 \\
\hline & Value 8. Experiments added credibility to physics & 0 & 2 & 0 \\
\hline & Underlying features: Practical work helped to overcome preconceptions (US) & & & \\
\hline & Total & 38 & 29 & 69 \\
\hline & Value 9. Development of didactic skills and thinking & 0 & 0 & 22 \\
\hline & $\begin{array}{l}\text { Underlying features: Gathering examples of how to use practical work as a teacher, understanding } \\
\text { how practical work can motivate students, understanding preconceptions (U) }\end{array}$ & & & \\
\hline \multirow[t]{7}{*}{ Negative } & $\begin{array}{l}\text { Criticism 1. Laboratories did not add content } \\
\text { Underlying features: Content was already taught in theory lessons (LS and U), experiments } \\
\text { provided no value for the matriculation examination (US) }\end{array}$ & 2 & 2 & 4 \\
\hline & Criticism 2. There was a shortage of surprises in the experiments & 3 & 3 & 0 \\
\hline & $\begin{array}{l}\text { Underlying features: A deductive approach was used (LS), the results of experiments were too } \\
\text { obvious (US) }\end{array}$ & & & \\
\hline & $\begin{array}{l}\text { Criticism 3. Experimentation was not well organized } \\
\text { Underlying features: Not enough time provided for experimenting (LS and U), no thinking required } \\
\text { or experiments were only tricks (LS), no proper reflection of results or teacher did not prepare the } \\
\text { experiments well enough beforehand leading to failures in experimenting (US) }\end{array}$ & 9 & 7 & 3 \\
\hline & $\begin{array}{l}\text { Criticism } 4 \text {. There were problems in combining theoretical content with the experiments conducted } \\
\text { Underlying features: There was not enough discussion to link experiments with theory } \\
\text { (LS, US, and U) }\end{array}$ & 4 & 1 & 2 \\
\hline & $\begin{array}{l}\text { Criticism 5. There were problems with facilities or equipment } \\
\text { Underlying features: Lack of equipment or broken equipment or no facilities (LS and US), lack of } \\
\text { guidance in the use of the necessary software (U) }\end{array}$ & 3 & 4 & 1 \\
\hline & Total & 21 & 17 & 10 \\
\hline
\end{tabular}

new things $(L S-1)$. Maybe the reasons underlying my point of view are that the experiments that we did were too obvious and one could tell just from the task assignment what would happen in the experiment $(L S-2)$. [Joe]
For Joe, practical work did not provide any new physics content even though he had had several experiences of practical work at lower secondary school. He did not feel that he had been learning any new theoretical content by doing practical work. He and two other research 
participants therefore considered the practical work that they had done useless, consisting of extra work with no surprises. Based on the whole of his essay response, we assume that Joe's teacher preferred deductive experiments where the results were also predetermined for the students. This kind of deductive instruction provided him with no real motivation and, according to his essay, he had not conducted any useful experiments. Two other preservice teachers also placed value only on a theoretical study of physics, while they had not been exposed to any useful experiments. Joe also mentioned that they worked in groups, but in his case we are unable to say whether it had been a positive or negative matter as far as he was concerned.

The preservice teachers' former physics teachers' actions and their methods of teaching physics were discussed in many essays. For instance, the following experimentally oriented preservice teacher Matt focuses on his teachers' actions when he discusses his upper secondary school experience of practical work:

At the upper secondary school our teacher for the first course was research-oriented and to my mind wasn't suited to the role of teacher. He demonstrated a few things but he simply announced the results, like Newton's laws and the conservation of energy (US - 3). On subsequent courses, we had another teacher and we did experiments that were considerably more illustrative and made us think $(U S+2)$. In my opinion, on that course it was made clear that you would get some divergence in your results. In physics experiments there are always some items of data that differ significantly from others $(U S+1, U S+4, U S+8)$. The biggest difference between lower and upper secondary school was that at upper secondary school we were given some [challenging] problems to solve [using practical work] $(U S+3)$. [Matt]

Here Matt identified a problem related to his first physics teacher's way of conducting demonstrations. In his opinion, the teacher did not sufficiently encourage discussion in the classroom. Similar findings were reported in seven essays concerning upper secondary teaching and nine essays concerning lower secondary teaching. Fortunately, it appears from what Matt writes that he thought that the second teacher obviously possessed rather better teaching skills. The students conducted illustrative experiments that activated their thinking and probably also their learning. The students also learned experimental skills, how to interpret data points, and acquired the ideas of scientific processes. At the upper secondary school Matt considered that the problems given to students to be solved by means of practical work were challenging, which in turn made them more interesting. In this entire excerpt Matt highlights a form of experimentation in which student thinking was also permitted to play a role. He was pleased when the teacher assigned them with tasks that encouraged them to reason about physics for themselves. Like Matt, other research participants also felt positively that they had learned about relevant practical skills during the experimentation (12 at lower secondary, 3 at upper secondary, and 18 at university) and had been motivated to learn science because of practical work ( 9 at LS, 7 at US, and 10 at $\mathrm{U})$.

Most of the preservice teachers referred to the BLT course when they described their university experience of practical work. For instance, Jake felt that the course provided an opportunity for him to think about the use of practical work at school from numerous perspectives:

In the Basic Laboratory Practice for Teachers we had the chance to think about the way in which practical work can be implemented in teaching at school, and also about how it can form a part of the teaching as a whole, and the aspects that should be emphasized for students in the different age-groups $(U+9)$. Earlier, I simply regarded doing experiments as a fun addition to my [university] studies $(U+3)$. A teacher needs to think about how an experiment will support the students' comprehensive understanding of the topic that is being studied $(U+9)$. [Jake]

Here Jake describes how his views of the use of practical work have changed during the BLT course. Earlier, before the BLT course, he had felt that practical work in traditional laboratory courses (such as the Millikan and Planck experiments mentioned previously) was merely an enjoyable extra to the university lectures. During this course, however, Jake has begun to understand the roles played by practical work in learning. He has now begun to regard practical work from a new perspective and to understand what kinds of setups can be used in lower and upper secondary school teaching and why practical work should be used as a part of physics teaching in general. Like Jake, 22 research participants had developed their didactic skills and thinking while undertaking practical work at university. Jake continues by emphasizing the role of practical work in linking theory and reality as follows:

The greatest advantage in practical work is the relationship it creates between scientific theory and socalled reality $(U+2)$-especially the experiments done by younger pupils where they can design, make and evaluate, which enhances their enthusiasm, interest $(L S+3)$ and trust in their own skills in learning science $(L S+1, L S+5)$. The use of practical work is probably not the easiest way for a teacher to organize teaching in the school classroom, but because of pupils' learning results and their motivation to learn $(U+2, U+3)$, it should play an important part in physics learning all the way through from elementary school. [Jake] 
Jake emphasizes the significance of a link between theory and reality. In our categorization this objective has been assigned to category 2 (see Table III). He considers practical work to be a way of making pupils enthusiastic, motivated, and interested in physics and for them to become confident in learning science. Based on his experience, the use of practical work should include aspects in which students can participate actively while conducting experiments, ranging from designing the experiment to evaluating the final results. Jake thinks that practical work should constitute a part of physics teaching at all of the school levels, but he also recognizes the challenges involved in organizing practical work.

In summary, these excerpts illustrate the general nature of students' essays. Evidently, the preservice teachers surveyed had experienced more practical work in their lower secondary school than in their upper secondary school. Practical work can, however, sometimes be regarded as a useless part of physics teaching and learning, especially when it is implemented poorly. On the other hand, successfully implemented practical work promotes the learning of physics and arouses interest in physics. After the BLT course, the preservice teachers considered practical work to constitute an important part of physics teaching and learning at school, even if it can be challenging for the teacher. The excerpts also indicate that physics teachers' skill in creating a social learning environment and their ability to challenge student thinking and to motivate students to learn science all play a significant role in implementing meaningful practical work at school.

\section{DISCUSSION AND CONCLUSIONS}

The objectives of practical work in physics teaching and learning have been raised in this article, and the article has also provided a theory-based categorization of the main objectives of practical work. The results have shown the kind of objectives that Finnish third-year preservice physics teachers emphasize when describing practical work at school and university and the kind of previous experience that they have of practical work.

\section{A. Preservice teachers' objectives}

Connecting theory with practice was the most frequently raised objective found in the preservice teachers' essays. This objective has previously also been seen by teachers [18] and by pupils [34] as important. It can be assumed that the teachers of the subject group have emphasized this objective in their teaching. Pekmez, Johnson, and Gott [42] have shown that the main reason for teachers to use practical work is that it "helps understanding, reinforces, backs up or illustrates or visualizes theory and cements knowledge." Our own interpretation for our results also emphasizes that the theory-practice link has been stressed in school teaching, in particular, in order to strengthen pupils' understanding of the science content, but teachers do not necessarily aim at, for example, developing ideas about the nature of science per se.

How to motivate students cropped up frequently in the preservice teachers' responses to our investigation. The importance of motivation as an objective of practical work was also emphasized by teachers and students in previous research $[6,32,33]$. Motivation can be seen as a positive reinforcing factor in learning processes. It would seem, in brief, that many teachers of the subject group have succeeded in creating motivating physics teaching by using practical work.

Objectives related to the introduction, observation, and understanding of phenomena also frequently occurred in the preservice teachers' essays. Students in the study by Wilkinson and Ward [33] likewise considered these objectives to be important, and the students of Hanif et al. [37] emphasized that they understood physics topics better as a result of practical work. One reason for these results can be found in the previous national curriculum, which particularly emphasized the role played by phenomena-based observations as a cornerstone of the learning process. This instructional approach has been termed the perceptional approach [43]. A characteristic of these most frequent objectives is that they are easy for preservice teachers to recognize and describe.

Furthermore, one-fifth of our preservice teachers stated that the use of practical work will offer new points of view in physics, as did the grade 12-13 pupils in the publication by Angell et al. [34]. Preservice teachers did not emphasize that becoming familiar with equipment would be an objective of practical work as much as did the first-year university students in research conducted by White et al. [36]. When their students were requested to assess a number of statements about practical work [36], they emphasized that one of the most important was concerned with learning to do experiments. Our preservice teachers, however, did not name this as an objective in itself when asked to describe freely the objectives of practical work. On the other hand, this may show how the use of questionnaires and predescribed statements may direct them to present ideas that they would otherwise not come up with so easily on their own.

In contrast, the preservice teachers in our study seldom introduced objectives concerning the enhancement of social and learning skills. This finding is in line with the results obtained with high school students by Wilkinson and Ward [33]. It can be assumed that these objectives are not generally recognized by students because they are less closely connected with physics than with the more or less general objectives of education. In addition, this objective has not been presented in earlier literature, and hence it may be missing from the teacher knowledge of the teachers of the subject group at lower and upper secondary schools.

Another important issue is that the objectives related to gaining an understanding of scientific processes and the nature of science did not appear in the preservice teachers' 
essays very often. This finding is obviously a result of the fact that the concept of nature of science can be demanding to define, and that only in the past 20 years or so has this issue formed a part of Finnish teacher education programs. As a consequence, ideas about the nature of science have not been introduced to most Finnish physics teachers in the course of their own teacher education. Abd-El-Khalick and Lederman [44] also suggest an explanation for the low number of comments related to NOS. They claim that it is unlikely that preservice teachers will be able to construct the kind of conceptual frameworks to be implicit in the course of their science teaching that would be necessary for an understanding of certain aspects of NOS. The same is probably also true in the case of our preservice teachers. Another explanation that Wilkinson and Ward [33] put forward is that teachers might not talk explicitly about the objectives of their teaching and hence their students may be unable to identify the objectives that their teachers have intended to attain.

Generally, it is not surprising that teachers often seem to lack sufficient understanding of the nature of science. Similar observations have been reported earlier $[45,46]$. On the other hand, there are certainly also teachers who present ideas about the nature of science in their teaching without recognizing them as such explicitly. It is, indeed, an obvious finding that our subjects did not recognize their own ideas that were related to the nature of science. This was also taken into account in our analysis in order to avoid any overinterpretation of the preservice teachers' expression of their own positions. Although the nature of science is a difficult topic for teachers and although it is also difficult as a research topic, based on our findings we would claim that our preservice teachers possess views that are at least partly similar to those held by the in-service teachers and students reported elsewhere in research articles published in this field [18,32-34,38,44-46].

In summary, some of the objectives of practical work set forth in position articles [5,7,9-11,17], and also in our national standards [47], are not understood as thoroughly by our preservice teachers as we would wish them to be. The desirable objectives, such as the achievement of an understanding of scientific process or of the nature of science, fail to be properly met at school or university. Furthermore, even if preservice teachers have participated in small group experiments at school, they may not consider this experience to foster social or learning skills. On the other hand, they have also experienced the use of practical work as a means of helping them to develop experimental skills, deepening their understanding of content, and hence that it can also enhance the motivation to learn science.

\section{B. Preservice teachers' experience}

Most of the preservice teachers' experience of practical work reported at school and university were positive, as were the experiences of students in research conducted by Hanif et al. [37]. The kinds of physics teaching that most commonly created a positive experience for subjects were teaching activities that developed students' practical skills and content understanding and fostered their motivation. Hence, the positive experiences were strongly related to the most central objectives of practical work and also to the success that a teacher had in achieving these by means of his or her work. Preservice teachers frequently emphasized the role played by students themselves in the process of conducting experiments. Their experiences were usually positive if they could actively participate in conducting experiments in small groups. Working in small groups can be seen as an activity related to the social competence that was also seen as important, especially at the school level, in the study conducted by Welzel et al. [18]. One of the outcomes of this process was the emergence of situations where preservice students were able to discuss and process the phenomena under examination. Their experience of their university laboratory courses was frequently also positive, whereas the students in the study conducted by White et al. [36] did not enjoy the use of practical work as much at university. In the situations that our preservice teachers experienced, the experiments that they were able to conduct personally enabled them to understand how practical work could also be used effectively in the school classroom.

On the other hand, most of the negative experiences of practical work seemed to have some connection with failures incurred in the implementation of practical work. According to Nott and Smith [48], "going wrong" in practical work is a normal part of obtaining results, and hence the failures could be used as learning opportunities. Similarly, Nott and Wellington [49] have proposed that teachers could use failed experiment as a starting point for explaining about science and scientists. Nott and Smith [48] have noted that teachers can "talk their way out of it" when students obtain incorrect results in the course of practical work. It is argued that teachers' responses to incidents are connected with their understanding of the actual nature of science [49]. Naturally, teachers also require a firm grasp of their subject matter so that they can analyze practical work in detail when dealing with real-world phenomena. Nott and Smith also emphasize that teachers should be trained to expect and exploit the incidents in practical work that will help them in integrating their teaching about the nature of science as part of their normal lessons [49]. Some of the negative experiences were related to problems experienced with laboratory facilities and resulting from a lack of equipment, but a skillful teacher can nevertheless do a lot of meaningful practical work with the aid of very modest facilities.

On the basis of the current study and also of our earlier research [50], we assume that the observed negative experiences of practical work were related to the general 
challenges faced by physics teachers in implementing practical work at the school level. Such challenges include (1) the limitations of laboratory facilities, (2) an insufficient knowledge of physics (both students' and teachers' knowledge), (3) a lack of instructional approaches, and (4) the general organization of practical work. Probably the most important shortcoming has been the absence of a general instructional approach: every teacher needs to have a general instructional approach that will guide his or her reasoning and actions as a teacher of physics.

In addition, many of the preservice teachers remarked on the minimal amount of practical work done at upper secondary schools. This observation is in line with our personal, empirical view of this issue. Teachers at upper secondary school level usually explain the limited amount of practical work by referring to problems such as lack of time and the large amount of content included in the curriculum [47]. This kind of argument leads to the question of the paucity of pedagogical content knowledge [51]. An experienced and skilful teacher will be able to analyze the content of the teaching and select the most important topics to be discussed thoroughly by reducing emphasis on the less important topics. Opportunities to implement practical work at the upper secondary level can be found using this approach: a skilful teacher will always be able to find ways to implement practical work even within restrictive time resources. It should, however, be noted that we did not investigate how the preservice teachers understood the concept of practical work. It is possible that, in some cases, students did not identify all of the conceivable types of empirical activity or the complements of practical work, such as thought experiments [52,53] or story narratives [54] as a form of practical work. Thus, the actual total number of experiences related to practical work may be larger than reported in the essays. As a consequence, this rather narrow conception of practical work may lead a student to conclude that she or he has undertaken only an inadequate amount of practical work as a school student.

According to our results there was a significant rise in the number of positive experiences at the university level, caused at least partly by the basic laboratory course for teachers. This indicates that preservice teachers are beginning to understand some of the objectives more explicitly when they attend the basic laboratory course for teachers (BLT), which discusses the use of practical work in physics teaching. In addition, a new objective category entitled "development of didactical skills and thinking" could also be identified. This particular category is not considered to be an objective of practical work as such, but it is certainly one of the objectives of the BLT course and of contemporary teacher education in general. Preservice teachers start to regard practical work as an essential part of teaching physics at the school level, and it seems that the course has begun to have a desirable influence on preservice teachers' thinking and attitudes.

\section{Future challenges and recommendations}

Knowledge of objectives is considered to be the cornerstone for implementing practical work in physics teaching at the school level $[14,55]$. Preservice teachers need to be offered opportunities for reflecting on, enhancing, and broadening their understanding of the objectives of practical work in school teaching. Their previous experience of practical work needs to be regarded as of explicit importance for preservice teachers because it is known that novice teachers frequently use their previous teachers as role models [56]. During the BLT course, preservice teachers often explained how their own teachers used to conduct particular demonstrations. By analyzing their earlier experiences, the preservice teachers can learn how successful teaching can be implemented and they can also gain an explicit understanding of the challenges of the practical work involved in physics teaching. This analysis can provide a basis for a real understanding of the objectives of practical work in school physics.

A future challenge will be for us to develop an environment where preservice teachers can confront the objectives of practical work and implement practical work that is directly related to the objectives presented here. We believe that preservice teachers' understanding of the objectives of practical work can be most effectively developed by offering them new and successful experiences of it. Explaining these things merely by lecturing about them is insufficient. In this way we may be able to offer preservice teachers a proper starting point for applying practical work in physics teaching at school. It also needs to be emphasized in teacher education that the amount of time that is devoted to practical work is not the main point; rather, the practical work must be well designed, with the objectives of the forthcoming actions specifically borne in mind.

To avoid any similar negative experience of the unsuccessful or failed experiments that our research participants had encountered, preservice teachers need to be trained properly in how to deal with such incidents. For example, the use of open-ended practical work could be used in teacher training so that preservice teachers can be asked to discuss, e.g., the outcomes, incidents, and reliability of their experiments. This will help them to develop their understanding of the nature of science and about ways in which to "talk their way out" [48] after the conclusion of experiments that fail to yield the expected results.

Even if preservice teachers to some extent understand the objectives of practical work, they may still face a challenge in transferring that knowledge to a school context at some future date. As stated in the theoretical background, not all of the objectives can be achieved simultaneously [9], but one has to make careful decisions about the single objectives that have been aimed at. In addition to the challenge of making preservice teachers more aware of the central objectives of practical work, it needs to be noted that, despite the numerous objectives 
facing them, in their own teaching they will need to concentrate on one or two objectives at a time. This aspect needs to be emphasized by educators in teacher training programs in order to ensure that practical work in schools will be undertaken purposefully and effectively.

Preservice teachers' remarks about the small amount of practical work at upper secondary school may be a cause for concern if the upper secondary school provides students with only a one-dimensional, theoretical view of physics. Physics, however, is both an empirical and a theoretical science, and therefore experiments play an essential role in its teaching. It is, then, a challenge for us to help in-service physics teachers to see the possibilities and advantages of practical work in the teaching of physics. It is well known that changing teachers' practices can be difficult. New teaching practices can only emerge as a result of changes either in a teacher's working environment or in his or her pedagogical content knowledge [57]. In-service teachers' pedagogical content knowledge can be developed through in-service training. If teachers become familiar with different ways of implementing practical work at school more effectively than in the past, changes in actual practices may occur. Even if the objectives of practical work are taken into account in the design and implementation of teaching, it cannot be guaranteed that pupils or students will understand the objectives of practical work [32] - even if the teacher is conscious of them. We should, therefore, also help our preservice teachers to develop the kind of pedagogical skills that will help them to obtain the necessary feedback from their students.

In light of all of the aspects presented above, it is clear that there is a need for further detailed observation of teachers' work and students' learning at the school level. In particular, we need more detailed information about the kind of practical work that is experienced positively. Positive experiences are needed if we seriously want to increase our students' motivation in their science studies. As a result of such research we can offer increased knowledge and concrete suggestions to help our preservice physics teachers to become aware of some of the aspects involved in the use of practical work in school physics teaching. As we have seen here, the requirements are varied. If discussions about the objectives of practical work do not occur during teacher education at university, there is a strong probability that practical work will be reduced to being a mere tool for the presentation of science content in a somewhat different way than in theory lessons.
[1] C. Crouch, A. Fagen, J. Callan, and E. Mazur, Classroom demonstrations: Learning tools or entertainment?, Am. J. Phys. 72, 835 (2004).

[2] N. D. Finkelstein, W. K. Adams, C. J. Keller, P. B. Kohl, K. K. Perkins, N. S. Podolefsky, S. Reid, and R. LeMaster, When learning about the real world is better done virtually: A study of substituting computer simulations for laboratory equipment, Phys. Rev. ST Phys. Educ. Res. 1, 010103 (2005).

[3] F. Reif and M.St. John, Teaching physicists' thinking skills in the laboratory, Am. J. Phys. 47, 950 (1979).

[4] E. Etkina, S. Murthy, and X. Zou, Using introductory labs to engage students in experimental design, Am. J. Phys. 74, 979 (2006).

[5] P. A. Kirschner and M. A. M. Meester, The laboratory in higher science education: Problems, premises and objectives, High. Educ. 17, 81 (1988).

[6] J. Kerr, Practical Work in School Science (Leicester University Press, Leicester, 1964).

[7] L. D. Shulman and P. Tamir, Research on teaching in the natural sciences, in Second Handbook of Research on Teaching, edited by R.M.W. Travers (Rand McNally, Chicago, 1973).

[8] J.W. Beatty and B.E. Woolnough, Practical work in 11-13 science: The context, type and aims of current practice, Br. Educ. Res. J. 8, 23 (1982) [http://www.jstor .org/stable/1500525].

[9] R. T. White, The link between the laboratory and learning, Int. J. Sci. Educ. 18, 761 (1996).
[10] American Association of Physics Teachers, Goals of the introductory physics laboratory, Am. J. Phys. 66, 483 (1998).

[11] A. Hofstein and V. N. Lunetta, The laboratory in science education: Foundations for the twenty-first century, Sci. Educ. 88, 28 (2004).

[12] D. Psillos and H. Niedderer, Issues and questions regarding the effectiveness of labwork, in Teaching and Learning in the Science Laboratory, edited by D. Psillos and $\mathrm{H}$. Niedderer (Kluwer, Dordrecht, 2002).

[13] J.D. Bransford, A.L. Brown, and R. R. Cocking, How people learn, in Brain, Mind, Experience, and School (National Academy Press, Washington, DC, 2000), expanded edition.

[14] A. Y. Kolb and D. A. Kolb, Learning styles and learning spaces: Enhancing experiential learning in higher education, Acad. Manag. Learn. Educ. 4, 193 (2005).

[15] D. A. Kolb, Experiential Learning: Experience as the Source of Learning and Development (Prentice-Hall, Englewood Cliffs, NJ, 1984).

[16] R. Millar and I. Abrahams, Practical work: Making it more effective, Sch. Sci. Rev. 91, 59 (2009).

[17] B. E. Woolnough, School science-real science? Personal knowledge, authentic science and student research projects, in Research in Science Education in Europe, edited by M. Bandiera, S. Caravita, E. Torracca, and M. Vicentini (Kluwer, Dordrecht, 1999), pp. 245-251.

[18] M. Welzel, K. Haller, M. Bandiera, D. Hammelev, P. Koumaras, H. Niedderer, et al., Teachers' objectives for 
labwork: Research tool and cross country results, http:// www.idn.uni-bremen.de/pubs/Niedderer/1998-LSE-WP6 .pdf, accessed 12 December 2009.

[19] D. K. Hodson, Rethinking old ways: Towards a more critical approach to practical work in science, Stud. Sci. Educ. 22, 85 (1993).

[20] J. Wilkinson and M. Ward, The purpose and perceived effectiveness of laboratory work in secondary schools, Aust. Sci. Teachers J. 43, 49 (1997).

[21] D. Hodson, Redefining and reorienting practical work in school science, in Teaching Science, edited by R. Levinson (Routledge, London, 1994), pp. 159-164.

[22] W. M. McComas, M. Clough, and H. Almazroa, The role and character of the nature of science in science education, in The Nature of Science in Science Education. Rationales and Strategies, edited by W. M. McComas (Kluwer Academic, New York, 1998).

[23] B.C. Palmquist and F. N. Finley, Preservice teachers' views of the nature of science during a postbaccalaureate science teaching program, J. Res. Sci. Teach. 34, 595 (1997).

[24] R. Millar, What is "scientific method" and can it be taught?, in Teaching Science, edited by R. Levinson (Routledge, London, 1994), pp. 165-178.

[25] M. Windschitl, J. Thompson, and M. Braaten, Beyond the scientific method: Model-based inquiry as a new paradigm of preference for school science investigations, Sci. Educ. 92, 941 (2008).

[26] A. Hofstein and V. N. Lunetta, The role of the laboratory in science teaching: Neglected aspects of research, Rev. Educ. Res. 52, 201 (1982).

[27] D. Hodson, Practical work in school science: Exploring some directions for change, Int. J. Sci. Educ. 18, 755 (1996).

[28] C. Hart, P. Mulhall, A. Berry, J. Loughran, and R. Gunstone, What is the purpose of this experiment? Or can students learn something from doing experiments?, J. Res. Sci. Teach. 37, 655 (2000).

[29] B. A. Crawford, Learning to teach science as inquiry in the rough and tumble of practice, J. Res. Sci. Teach. 44, 613 (2007).

[30] D. Hodson, Laboratory work as scientific method: Three decades of confusion and distortion, J. Curric. Stud. 28, 115 (1996).

[31] C. A. R. Berg, V. C. B. Bergendahl, B. K. S. Lundberg, and L. A.E. Tibell, Benefiting from an open-ended experiment? A comparison of attitudes to, and outcomes of, an expository versus an open-inquiry version of the same experiment, Int. J. Sci. Educ. 25, 351 (2003).

[32] I. Abrahams and M. Saglam, A study of teachers' views on practical work in secondary schools in England and Wales, Int. J. Sci. Educ. 32, 753 (2010).

[33] J. Wilkinson and M. Ward, A comparative study of students' and their teacher's perceptions of laboratory work in secondary schools, Res. Sci. Educ. 27, 599 (1997).

[34] C. Angell, O. Guttersrud, E. K. Henriksen, and A. Isnes, Physics: Frightful, but fun. Pupils' and teachers' views of physics and physics teaching, Sci. Educ. 88, 683 (2004).

[35] M. Braund and M. Driver, Pupils' perceptions of practical science in primary and secondary school: Implications for improving progression and continuity of learning, Educ. Res. 47, 77 (2005).

[36] R. White, R. Gunstone, E. Elterman, I. Macdonald, B. Mckittrick, D. Mills, and P. Mulhall, Students' perceptions of teaching and learning in first-year university physics, Res. Sci. Educ. 25, 465 (1995).

[37] M. Hanif, P. H. Sneddon, F. M. Al-Ahmadi, and N. Reid, The perceptions, views and opinions of university students about physics learning during undergraduate laboratory work, Eur. J. Phys. 30, 85 (2009).

[38] N.S. Edward, The role of laboratory work in engineering education: Student and staff perceptions, Int. J. Electr. Eng. Educ. 39, 11 (2002).

[39] K. Krippendorff, Content Analysis: An Introduction to Its Methodology (Sage, Thousand Oaks, CA, 2004), 2nd ed.

[40] S. Kvale, InterViews. An Introduction to Qualitative Research Interviewing (Sage, Thousand Oaks, CA, 1996).

[41] M. A. Burmester, The construction and validation of a test to measure some of the inductive aspects of scientific thinking, Sci. Educ. 37, 131 (1953).

[42] E. S. Pekmez, P. Johnson, and R. Gott, Teachers' understanding of the nature and purpose of practical work, Res. Sci. Technol. Educ. 23, 3 (2005).

[43] P. Hirvonen and J. Viiri, Physics student teachers' ideas about the objectives of practical work, Sci. Educ. 11, 305 (2002).

[44] F. Abd-El-Khalick and N. G. Lederman, Improving science teachers' conceptions of nature of science: A critical review of the literature, Int. J. Sci. Educ. 22, 665 (2000).

[45] N. G. Lederman, Students' and teachers' conceptions of the nature of science: A review of the research, J. Res. Sci. Teach. 29, 331 (1992).

[46] R.S. Schwartz, N. G. Lederman and B. A. Crawford, Developing views of nature of science in an authentic context: An explicit approach to bridging the gap between nature of science and scientific inquiry, Sci. Educ. 88, 610 (2004).

[47] The Finnish National Board of Education (FNBE), National Core Curriculum for Upper Secondary Schools 2003 (Vammalan kirjapaino, Vammala, 2003).

[48] M. Nott and R. Smith, 'Talking your way out of it', 'rigging' and 'conjuring': What science teachers do when practicals go wrong, Int. J. Sci. Educ. 17, 399 (1995).

[49] M. Nott and J. Wellington, When the black box springs open: Practical work in schools and the nature of science, Int. J. Sci. Educ. 18, 807 (1996).

[50] V. Nivalainen, M.A. Asikainen, and P.E. Hirvonen, Preservice and inservice teachers' challenges in the planning of practical work in physics, J. Sci. Teach. Educ. 21, 393 (2010).

[51] L. D. Shulman, Knowledge and teaching: Foundations of the new reform, Harv. Educ. Rev. 57, 1 (1987).

[52] J. Gilbert and M. Reiner, Thought experiments in science education: Potential and current realization, Int. J. Sci. Educ. 22, 265 (2000).

[53] I. Galili, Thought experiments: Determining their meaning, Sci. Educ. 18, 1 (2009).

[54] S. Klassen, The science thought experiment: How might it be used profitably in the classroom?, Interchange 37, 77 (2006). 
[55] G. Sánchez and M. V. Valcárcel, Science teachers' views and practices in planning for teaching, J. Res. Sci. Teach. 36, 493 (1999).

[56] F. A. J. Korthagen, Linking practice and theory: The pedagogy of realistic teacher education, in Proceedings of the Annual Meeting of the American Educational Research
Association, Seattle, Washington, 2001, http://resources .educ.queensu.ca/ar/aera2001/Korthagen2001.pdf.

[57] M. Monk, S. Johnson, and J. Swain, Modelling adaptation in the evolution of an in-service programme: Blind variation and selective retention in school-based observation activities, J. Serv. Educ. 24, 429 (1998). 